\title{
Effect of Culture on Acceptance of Telemedicine in Middle Eastern Countries: Case Study of Jordan and Syria
}

\author{
Mohannad Alajlani, PhD, and Malcolm Clarke, PhD \\ Information Systems and Computing, Brunel University, Uxbridge, \\ Middlesex, United Kingdom.
}

\begin{abstract}
We investigated issues that affect the use and adoption of telemedicine in Middle Eastern countries, taking the Hashemite Kingdom of Jordan and the Syrian Arab Republic as case studies. Our study is based on interviews with key stakeholders (including doctors, technicians, engineers, and decision makers) and questionnaires administered to key stakeholders (including patients), ensuring opinion was gained from people from a full range of backgrounds and roles in the healthcare system. We found doctor and patient resistance was a major issue preventing the adoption of telemedicine in both countries, followed by poor infrastructure, lack of funding, and lack of information technology training. Our research identifies that culture is a greater issue than technical matters for the adoption of telemedicine in Middle Eastern countries. Based on our preliminary results we developed a guideline framework for each country that might be applied to telemedicine projects at the pre-implementation phase. The proposed guideline framework was validated through a return visit to the stakeholders and seeking further opinion.
\end{abstract}

Key words: e-health, telemedicine, telehealth

\section{Introduction}

- elemedicine delivers healthcare between geographically separated locations using medical expertise supported by communication technology. Physicians and specialists from one site provide diagnosis, treatment, and consultation to patients at a remote site. This makes the use of telemedicine particularly effective in rural and remote areas that have limited access to healthcare services. This phenomenon may be clearly observed in such areas in developed countries and some developing countries.

Telemedicine has been much improved and has become significantly enhanced, but many problems continue to obstruct its application. This study investigates the issues that affect the use and adoption of telemedicine in the Hashemite Kingdom of Jordan (Jordan) and the Syrian Arab Republic (Syria). These countries would appear to have many aspects, including technology infrastructure, policies, and culture, in common. Taking two countries with many common aspects makes the study significant as the results from the analysis may be generalized and transferred. The study was limited by the lack of projects in both countries and particularly in Syria. Moreover, no projects have been reported, resulting in a lack of literature on which to make comparison. This is the first work to undertake a systematic survey of telemedicine activity in the two countries and to determine attitude and barriers.

This compares with other Middle Eastern countries, such as Saudi Arabia, where there is clear and growing interest and use. ${ }^{1}$ This article determines the factors pertinent to these two countries and compares them with other countries in the region. Religion, culture, politics, history, and economic factors are often suggested as being most relevant to this region. ${ }^{2}$ of these, although culture is often cited as a concern, it is not expressed as a barrier.

This work is the first to undertake a systematic survey of telemedicine activity in the two countries to determine attitude and barriers. It investigates the differences in awareness and cultural issues between Jordan and Syria with comparison regarding the culture issues surrounding the adoption of telemedicine. Such differences may be the result of many country-specific reasons, such as infrastructure, education, economics, and politics. The guideline frameworks, if followed prior to the establishment of any telemedicine project, will provide clear information on the current level of e-health readiness of each country and help direct the focus for the essential concerns affecting the success of the project. Moreover, this work is a preliminary study that can be widely generalized to include other countries in the Middle East, other developing countries, and rural areas with similar characteristics and can be an initial step in analyzing the readiness of a country seeking to adopt any other e-health application.

\section{National Characteristics}

Table 1 provides a comparison of salient national statistics of the two countries, including population, gross domestic product, and the government budget on health and education.,

Jordan spends more on education, ranking 76th in the world. ${ }^{3}$ Syria ranks 109th. ${ }^{4}$ This may explain why the public in Jordan is more literate and knowledgeable about technology and why the country has a better infrastructure and higher Internet usage. Health expenditure in Jordan $^{5}$ is also higher than Syria. ${ }^{6}$ These characteristics may lead people in Jordan to have more familiarity with the concept of telemedicine and therefore will see telemedicine projects being funded.

\section{Materials and Methods}

The study took place in Jordan and Syria in the period JanuaryJuly 2010 and was designed to elicit opinion on the cultural issues that affect the adoption and use of telemedicine in each country. 


\section{ALAJLANI AND CLARKE}

\begin{tabular}{l|c|c} 
Table 1. National Statistics & JORDAN & SYRIA \\
\hline Population (2009) & $6,269,285$ & $21,762,978$ \\
\hline GDP per capita (US dollars) (2009) & 5,300 & 4,600 \\
\hline GDP on education expenditure (\%) (1999) & 4.9 & 3.9 \\
\hline Unemployment rate (\%) (2009) & 13.5 & 9.2 \\
\hline Internet usage (\%) (2008) & 24 & 16.3 \\
\hline GDP on health expenditure (\%) & 5.6 & 4 \\
\hline
\end{tabular}

GDP, gross domestic product.

Data were collected through questionnaires (Table 2) and interviews with the key stakeholders, including doctors, technicians, engineers, decision makers, and patients. The research had ethical approval from the Brunel University Research Ethics Committee. An Ethical Approval Certificate was issued and was presented to the key stakeholders before their interviews.

One hundred participants (50 in each country) were asked to complete the questionnaires to determine their awareness and acceptance of telemedicine. Questionnaires were handed out to each participant to ensure there was no delay in receiving the responses. All participants were between the age of 25 and 65 years and selected from both urban and rural districts of each country. A further 45 professional participants (22 in Jordan and 23 in Syria) were given face-to-face semistructured interviews to gain detailed opinions of the issues. Interviewees in both countries were selected for this study as being employed by the respective research and development departments in the Ministry of Health and the Ministry of Telecommunications.
Further interviewees were selected on recommendation by the initial interviewees. Additional clinical interviewees were added through personal acquaintance with the researchers.

Prospective interviewees were called in advance and asked if they were willing to participate in the study, and appointments were booked in order to meet with them. Participants for interview were included from a representative set of backgrounds: urban, rural; hospital clinic; consultant, general practitioner; Accident and Emergency department (A\&E), dialysis units; administrative, technical; and Ministry (Health and Telecommunications). Participants were selected as having appropriate knowledge to participate in this research and were between the age of 25 and 65 years. All were selected from both urban and rural districts of each country as shown in Tables 3 and 4. Interviews were analyzed using thematic analysis: "a method of qualitative analysis based on participants' conceptions of actual communication episodes; a theme is identified based on recurrence, repetition, and forcefulness."7

\section{Results}

Although neighboring countries in the Middle East with similar demographics (Table 1), there are significant differences in responses between Jordan and Syria (Table 2). The awareness of telemedicine between Jordan and Syria was investigated by using chi-squared statistics, and the difference was defined as significant at the 5\% level. Questions relating to culture issues indicate that these have the largest effects on the adoption of telemedicine in both countries. The reasons are explored in greater detail within the interviews, and results are presented in the following sections.

\section{INFRASTRUCTURE}

Infrastructure was identified as a major difference between the two countries: Jordan embraced the use of technology many years ahead

\begin{tabular}{|c|c|c|c|c|c|c|}
\hline \multirow[b]{2}{*}{ QUESTION } & \multicolumn{3}{|c|}{ JORDAN } & \multicolumn{3}{|c|}{ SYRIA } \\
\hline & $\begin{array}{l}\text { YES } \\
(\%)\end{array}$ & $\begin{array}{c}\text { NOT } \\
\text { MUCH } \\
(\%)\end{array}$ & $\begin{array}{l}\text { NO } \\
(\%)\end{array}$ & $\begin{array}{l}\text { YES } \\
(\%)\end{array}$ & $\begin{array}{c}\text { NOT } \\
\text { MUCH } \\
(\%)\end{array}$ & $\begin{array}{l}\text { NO } \\
(\%)\end{array}$ \\
\hline Q-1. Have you ever had any experience of any type of telemedicine before? & 72 & 0 & 28 & 18 & 0 & 82 \\
\hline Q-2. Do you use technology (e-mail, mobile phone, etc.) to obtain knowledge about healthcare? & 86 & 0 & 14 & 32 & 0 & 68 \\
\hline Q-3. Would you prefer to be diagnosed via telemedicine, or to be diagnosed by a doctor in person? & 18 & 0 & 82 & 8 & 0 & 92 \\
\hline Q-4. Do you think applying telemedicine in (Jordan) (Syria) will be useful? & 58 & 28 & 14 & 42 & 14 & 44 \\
\hline Q-5. Do you think telemedicine will be affected negatively by the culture and religion issues? & 28 & 16 & 56 & 62 & 10 & 28 \\
\hline Q-6. Do you think people in (Jordan) (Syria) are willing to use telemedicine? & 62 & 18 & 20 & 34 & 14 & 52 \\
\hline Q-7. Do you think technical issues have a potential impact on applying telemedicine? & 86 & 6 & 8 & 78 & 10 & 12 \\
\hline Q-8. Do you think social issues (culture or religion) have a potential impact on applying telemedicine? & 54 & 20 & 26 & 48 & 20 & 32 \\
\hline Q-9. Do you think the government should make available more funds for telemedicine projects? & 90 & 4 & 6 & 86 & 6 & 8 \\
\hline Q-10. Do you think the government should amend policies in order to support telemedicine projects? & 60 & 8 & 32 & 90 & 6 & 4 \\
\hline
\end{tabular}


Table 3. Interviewees in Jordan

CATEGORY, JOB POSITION

\begin{tabular}{c|c} 
MALE/FEMALE & PRIVATE/PUBLIC \\
SECTOR
\end{tabular}
URBAN/RURAL

AREA

Decision makers

\begin{tabular}{|c|c|c|c|}
\hline Director Directorate of Information, Studies and Research, Ministry of Health & Male & Public & Urban \\
\hline Colonel in the Royal Medical Centre & Male & Public & Urban \\
\hline Owner of a hospital & Male & Private & Urban \\
\hline \multicolumn{4}{|l|}{ Doctors } \\
\hline Ophthalmologist & Male & Private & Rural \\
\hline Ophthalmologist & Male & Private & Urban \\
\hline General practioner & Male & Private & Urban \\
\hline Accident and Emergency department & Female & Public & Rural \\
\hline Accident and Emergency department & Male & Public & Rural \\
\hline Dentist & Male & Public & Rural \\
\hline Dentist & Male & Private & Urban \\
\hline Anesthetist & Male & Public & Urban \\
\hline Surgeon & Male & Public & Urban \\
\hline Radiologist & Male & Private & Urban \\
\hline \multicolumn{4}{|l|}{ Paramedics } \\
\hline Nurse & Male & Public & Rural \\
\hline Nurse & Female & Private & Urban \\
\hline \multicolumn{4}{|l|}{ Technicians } \\
\hline Network engineer & Male & Private & Urban \\
\hline Quality assurance engineer & Male & Private & Urban \\
\hline \multicolumn{4}{|l|}{ Others } \\
\hline Director, marketing department, telecommunication company & Male & Private & Urban \\
\hline Financial manager, trade company & Male & Private & Urban \\
\hline Lecturer, PhD in computer science & Male & Private & Urban \\
\hline Statistician, Ministry of Statistics & Female & Public & Urban \\
\hline Owner of importing and exporting company & Male & Private & \\
\hline
\end{tabular}

of Syria. This has resulted in a far more advanced infrastructure being in place, with doctors and patients having a greater awareness of its potential and with several telemedicine projects already existing. The majority of its doctors and healthcare providers are aware of telemedicine, although not all understand its benefits. Although the proper infrastructure is available in urban areas, adoption of telemedicine is slow, and its applications are not being used.

In contrast, Syria is in the early stages of technological development and has no experience with telemedicine applications (except a very small percentage of doctors who use e-mail to obtain a second opinion). The infrastructure of the country is poor and unsuitable for supporting telemedicine projects. The majority of doctors and healthcare providers are unaware of telemedicine applications. Moreover, Syria has many barriers that impede adoption of telemedicine such as import control.

\section{FUNDING}

Funding is considered a major barrier to telemedicine in Jordan. However, most of the interviewees in Syria did not see that funding could create a major barrier to telemedicine; this point of view was 


\section{ALAJLANI AND CLARKE}

\section{Table 4. Interviewees in Syria}

CATEGORY, JOB POSITION

Decision makers

\begin{tabular}{|c|c|c|c|}
\hline Deputy Minister of Communication & Male & Public & Urban \\
\hline Head of the IT and Decision Making Department, Ministry of Health & Female & Public & Urban \\
\hline Founder of the Syrian Computer Society for Informatics & Male & Private & Urban \\
\hline Member of Chamber's Bureau, Chamber of Industry & Male & Public & Urban \\
\hline Owner of a hospital & Male & Private & Urban \\
\hline \multicolumn{4}{|l|}{ Doctors } \\
\hline Anesthetist and head of operations & Male & Private & Rural \\
\hline Pathologist & Male & Private & Rural \\
\hline Pathologist & Male & Private & Urban \\
\hline Ophthalmologist & Male & Private & Urban \\
\hline Accident and Emergency department & Male & Public & Rural \\
\hline Surgeon & Male & Public & Rural \\
\hline Radiologist & Male & Private & Urban \\
\hline \multicolumn{4}{|l|}{ Paramedics } \\
\hline Nurse & Female & Public & Rural \\
\hline Nurse & Male & Private & Urban \\
\hline Nurse & Male & Private & Urban \\
\hline \multicolumn{4}{|l|}{ Technicians } \\
\hline Medical engineer & Female & Public & Rural \\
\hline Medical engineer & Male & Public & Urban \\
\hline Electrical engineer & Female & Private & Rural \\
\hline Telecommunication engineer & Male & Private & Urban \\
\hline \multicolumn{4}{|l|}{ Others } \\
\hline Financial manager, auditing company & Male & Private & Urban \\
\hline Financial auditor & Male & Private & Urban \\
\hline Owner of a factory, electrical machines & Male & Private & Urban \\
\hline Owner of importing and exporting company & Male & Private & Urban \\
\hline
\end{tabular}

$\mathrm{IT}$, information technology.

due to the lack of understanding of telemedicine and in particular how it is implemented and what its costs might be: "All what we need is two laptops and a Web cam, right?" (owner of a hospital, Damascus).

Most of the private clinics and hospitals in Jordan are well funded as it is believed that hospitals are an investment and business; the better the services they provide, the greater the success. However, problems remain in the public hospitals, particularly in remote areas.
The public healthcare services are in need of funding and support so that improvements can be made. At 5.6\% of gross domestic product, investment in health is low in comparison with many developed countries and, in absolute terms, is only sufficient to maintain existing healthcare services, with little for investment in new techniques: "The government is doing its best to support the healthcare field but it has a limited budget, that's why we all have to support and help to raise the quality of healthcare" (owner of a hospital, Amman). 


\section{TELEMEDICINE IN MIDDLE EASTERN COUNTRIES}

Although the country is relatively wealthy, insufficient funding is being invested in telemedicine, with investment occurring only in a few private hospitals and clinics, and this is only to support basic telemedicine. This is partly explained as it currently is not perceived as having business advantage: "Why shall I risk my money in a project that may not give me good profit in return? It is still unclear how it will work and how we can get income from it" (dentist, Amman).

Most interviewees identified higher priority needs for funding and considered that it should be concentrated on providing mainstream medical devices (such as magnetic resonance imaging) in public hospitals and health centers. However, it should improve the information technology (IT) infrastructure and provide equipment to support telemedicine (computers and telecommunication devices, etc.). Many highlighted the need for funding to provide training for doctors, nurses, and all other staff that are involved in telemedicine applications. Although many of the medical staff and the paramedics had learned about telemedicine in university or college, they had never experienced using it because of lack of IT training. Today they wish to gain knowledge about it, but there is no resource to support it: "I have been working in public hospitals for 20 years and have never taken any course related to healthcare or IT. How can I run a telemedicine application?" (A\&E doctor, rural area).

In contrast, Syria will require significant investment on its infrastructure as it is in such poor condition, in addition to any other funding to support the introduction of telemedicine. There also need to be efforts for collaboration between the separate ministries (Health and Communications) in order to create the required conditions for adoption: "We will ask the government to fix the infrastructure before we think about establishing such a project; we are talking about a fortune here" (telecommunication engineer, Damascus). However, the Ministry of Health and the Ministry of Communication are currently unwilling to fund such a project as they are unsure if it will yield benefits. Instead, they are waiting on the private sector to establish a telemedicine project to prove the case, and then they will make a decision: "We will not stop anyone from establishing a telemedicine project, but we will not be involved until we see good results" (head of decision making department, Ministry of Health).

This lack of knowledge emphasizes the need for training courses and IT education for the public and the staff who will be involved in telemedicine, such as doctors, paramedics, technicians, and decision makers, so they can become aware of the benefits that can be gained from adopting telemedicine projects.

\section{RESISTANCE}

The study found that doctor and patient resistance is a significant barrier in both countries; however, there was important variation between them. Doctor resistance is higher in Syria than in Jordan, with most of the doctors in Syria being opposed to the idea of telemedicine as they had had no previous experience of it, and they expressed concern about changing to this new technology: "I don't know if I can run such a project, I feel it is too advanced for me" (A\&E doctor, rural area). In contrast, patient resistance is higher in Jordan, with many of the female patients expressing concern about the background of the doctor with whom they would be consulting (in the case of video consultation, for instance). Although religion was not cited as a barrier to telemedicine, female patients in general prefer to be diagnosed in a culturally sensitive way. They prefer their body to be fully covered (if the doctor is male) and to uncover only the part that needs to be examined: "The religion never prevents us from looking after our health, it is only the culture of people. ... Patients should be examined in a special way known by doctors, especially when the patient is a woman, and according to the culture, she would prefer to cover her body and only reveal the part that needs to be diagnosed, which has nothing to do with religion" (general practitioner, Amman).

There is resistance from both the public and private sectors to the use of telemedicine before they have even observed how it functions. This was most noticeable in Syria because of the lack of knowledge: "We were a closed country, we had a hard time regarding technology use, but now we are hoping to exploit this technology properly and follow the world's evolution" (owner of a factory, Damascus).

Resistance in Jordan was explained by concerns over what might happen after a telemedicine project has been adopted, such as running out of funds. On the other hand, doctors in Syria explained they were apprehensive that telemedicine might threaten their careers as they are unable to predict the consequences of adopting such an approach.

\section{AWARENESS OF TECHNOLOGY}

The study found a significantly higher number of people in Jordan with knowledge about telemedicine. However, in both cases there remains the need for training to be provided to medical staff in order to run telemedicine efficiently.

\section{GOVERNMENTAL PROCEDURES}

Neither government prohibits telemedicine projects in their country, but the complex and time-consuming import procedures for medical devices in Syria are inhibiting adoption of technology in healthcare and telemedicine in particular. This emphasizes the need for public-private partnerships in Syria as the government can relax the procedures for importing devices by providing exemptions. The procedures for importing medical devices are easier in Jordan.

\section{GUIDELINE FRAMEWORK}

From our results we developed a guideline framework that might be applied pre-implementation to determine the state of readiness of a country for telemedicine. The guideline framework is based on assessment of the status of the country (or region) on the important strategic factors identified within our study. Although we recognize that pilots and small scale are a typical first step, we have sought to determine the factors that would most influence wide-scale adoption. We apply the framework to Jordan and Syria in Table 5 to identify the most important factors for adoption of telemedicine and highlight the main differences between Jordan and Syria. 


\section{ALAJLANI AND CLARKE}

\begin{tabular}{|c|c|c|}
\hline & JORDAN & SYRIA \\
\hline Infrastructure & $\begin{array}{l}\text { Available and appropriate to support } \\
\text { adoption of telemedicine projects in } \\
\text { urban areas; poor in rural areas }\end{array}$ & $\begin{array}{l}\text { Poor in urban and rural areas and } \\
\text { unsuitable to support telemedicine } \\
\text { projects }\end{array}$ \\
\hline Awareness of telemedicine & $\begin{array}{l}\text { - Doctors are aware of telemedicine } \\
\text { applications. } \\
\text { - A large number of people are aware } \\
\text { of telemedicine applications. }\end{array}$ & $\begin{array}{l}\text { - Only a small number of doctors are } \\
\text { aware of telemedicine applications. } \\
\text { - A small number of people are aware } \\
\text { of telemedicine applications. }\end{array}$ \\
\hline Funding & Major barrier & $\begin{array}{l}\text { Reported as minor barrier (may be due } \\
\text { to the lack of knowledge related to the } \\
\text { cost of telemedicine projects) }\end{array}$ \\
\hline Resistance & $\begin{array}{l}\text { - Patients resist the adoption of tele- } \\
\text { medicine more than doctors. } \\
\text { - There are concerns about the issues } \\
\text { that might occur during and after } \\
\text { adopting telemedicine projects. }\end{array}$ & $\begin{array}{l}\text { Doctors resist the adoption } \\
\text { of telemedicine more than patients. } \\
\text { - There are concerns before adopting } \\
\text { telemedicine projects. }\end{array}$ \\
\hline Governmental procedures & $\begin{array}{l}\text { Standard procedures to import medical } \\
\text { devices }\end{array}$ & $\begin{array}{l}\text { Complex procedures to import medical } \\
\text { devices }\end{array}$ \\
\hline Other issues & Internet is secure & Lack of Internet security \\
\hline
\end{tabular}

available resources, and this has helped to overcome the barriers of the adoption of telemedicine.

In contrast, countries such as Jordan and Syria could use the resources they have to adopt telemedicine applications efficiently, but culture issues, including doctor and patient resistance, impede the process of the telemedicine adoption. The study did find that the major issue articulated by the participants preventing the adoption of telemedicine in both countries is doctor and patient resistance; followed by poor infrastructure, lack of funding, and lack of IT training. In addition, there are patients who have concerns about being connected to doctors from a different social background, leading to misunderstanding and feeling uncomfortable with the way the doctor is diagnosing them.

There is a clear lack of development of telemedicine within Jordan and Syria and a complete absence of telemedicine projects in Syria. Although participants

\section{VALIDATION}

The outcome of the guideline framework was discussed with some of the same key stakeholders in order to validate the framework and elicit opinions on the readiness of each country for telemedicine and on future strategy.

Stakeholders expressed the opinion that the framework captured their needs well and would be useful to assess the readiness of the healthcare system in each country to use telemedicine and to assist any healthcare provider who might be considering implementing a telemedicine project. Moreover, the key stakeholders were optimistic that if the guideline framework was promoted to policy makers, it would help them understand the benefits of the telemedicine applications and facilitate their adoption. Furthermore, the guideline framework could be found helpful in analyzing the readiness of other countries with similar circumstances that are seeking to adopt any e-health application.

\section{Discussion}

Telemedicine is changing rapidly as the technology develops, and the Middle East is following this growth despite the technical and culture problems. It can be clearly anticipated that telemedicine will be important in the Middle East: it can improve access to healthcare for people living in remote regions, and it can improve the local economy by reducing the need for people to travel abroad for consultation. ${ }^{8}$ Despite all the barriers that face the adoption of telemedicine, there is interest in telemedicine applications in the Middle East, and this is evidenced by projects in countries such as the United Arab Emirates and Saudi Arabia. ${ }^{1}$ However, these countries have good funding, well-developed infrastructure, and were easily recruited to the study, the lack of knowledge of telemedicine and its benefits was evident in the responses to the questionnaires and in the interviews. Syria is also a relatively closed country, and there is general lack of adoption of new technology. These factors clearly influenced outcome. Furthermore, it will be necessary to overcome the resistance of the decision makers, as they have an essential role in changing government policy to support, fund, and give greater priority to telemedicine approaches.

\section{Conclusions}

Middle Eastern countries, like the rest of the world, have become highly dependent on new technology in almost all aspects of modern life, including communication and medical science. ${ }^{1}$

This study identifies that lack of awareness is a major barrier. This will be overcome through knowledge of activities in the region, widescale adoption elsewhere, and introduction of pilot studies to the country. This would therefore indicate that telemedicine can grow rapidly once conditions are opportune.

The study will be promoted to government and decision makers in these countries in order to increase awareness and so advocate the use of telemedicine in Jordan and make efforts to establish the first telemedicine project in Syria. Moreover, this study can be generalized to include other countries in the Middle East, other developing countries, and rural areas with similar characteristics in order to spread the use of telemedicine in the countries that most need it.

\section{Disclosure Statement}

No competing financial interests exist. 


\section{REFERENCES}

1. Al-Damen E. Validity of telemonitoring home care services in Saudi Arabia [Master's dissertation]. 2010. Available at http://ebookbrowse.com/validity-oftelemonitoring-home-care-services-in-saudi-arabia-pdf-d54498295 (last accessed March 18, 2013).

2. Al-Shorbaji N. WHO EMRO's approach for supporting e-health in the Eastern Mediterranean. East Mediterr Health J 2006;12:38-52.

3. Central Intelligence Agency. The World Fact Book. 2010. Available at www.cia.gov/library/publications/the-world-factbook/geos/jo.html (last accessed April 14, 2010).

4. Central Intelligence Agency. The World Fact Book. 2010. Available at www.cia.gov/library/publications/the-world-factbook/geos/sy.html (last accessed April 14, 2010).

5. Directorate of Information and Studies. The Hashemite Kingdom of Jordan Ministry of Health: Annual statistical book. 2007. Available at www.moh.gov.jo/MOH/Files/Publication/REPORT2007.pdf (last accessed May 7, 2009).

6. Ministry of Health. Health indicators. 2008. Available at www.moh.gov.sy/en/ Statistics/HealthIndicators/tabid/337/portalid/0/Default.aspx (last accessed April 15, 2010).
7. Keyton J. Communication research: Asking questions, finding answers. New York: McGraw-Hill, 2011:311-316.

8. Amin H, Gher L. Digital communications in the Arab World. In: Amin H, Gher L, eds. Civic discourse and digital age communications in the Middle East. New York: Ablex Publications, 2011:109-140.

Address correspondence to: Malcolm Clarke, $\mathrm{PhD}$

Information Systems and Computing

Brunel University

Uxbridge, Middlesex, UB8 $3 P H$

United Kingdom

E-mail: malcolm.clarke@brunel.ac.uk

Received: April 27, 2012

Revised: August 18, 2012

Accepted: August 20, 2012 